\title{
VALIDASI SKALA SIKAP TERHADAP PELAJARAN MATEMATIKA DAN SAINS
}

\author{
Jelpa Periantalo* \\ Marlita Andhika Rahman* \\ Hera Wahyuni*** \\ Fadzlul* \\ *Program Studi Psikologi, Fakultas Kedokteran dan Ilmu Kesehatan, Universitas Jambi \\ **Program Studi Bimbingan Konseling, Fakultas Keguruan dan Ilmu Pendidikan, Universitas Jambi
}

DOI: http://doi.org/10.21009/JPPP.092.02

\begin{abstract}
Alamat Korespondensi:
Jelp.8487@unja.ac.id
\end{abstract}

\begin{abstract}
The purpose of this study is to validate the Attitude Scale toward Math and Sciences subject compare to other measurement criteria. In this study, there were four subjects tested, including math, biology, physics, and chemistry. This test was validated by other tests, such as Tes Potensi Akademik (TPA), Tes Minat Indonesia specification health sciences, and the national exam. There were 549 first-year students of Faculty Medicine and Health Sciences in Universitas Jambi were included as the sample od the study. It was found that there was positive correlation between Tes Potensi Akademik (TPA) and math score $\left(p_{x y}=0.238\right)$, chemistry score $\left(p_{x y}=0.200\right)$, and biology score $\left(p_{x y}=0.163\right)$. However, there was no correlation between Tes Potensi Akademik (TPA) and physics score $\left(p_{x y}=-0.044\right)$. Positive correlation was found between Tes Minat Indonesia specification health sciences and biology $\left(p_{x y}=0.173\right)$, and chemistry $\left(p_{x y}=0.148\right)$. Positive relationship was also showed between national exam and math score $\left(p_{x y}=0.373\right)$, then chemistry score $\left(p_{x y}=0.235\right)$. Data and instrument gathered in this study were available as the learning resources, as the validator of the other studies, learning outcome evaluation, specialization in high school or aptitude test. To achieve stronger result in the future, researcher may validate this instrument with greater subjects and GPA as the indicator of academic achievement among students
\end{abstract}

Keywords

Attitude, validity, interest, correlation, spearman rho, criterion

\section{Pendahuluan}

Periantalo, Fadzlul dan Saputra (2014) melakukan pengumpulan terhadap bukti dari validitas skala sikap terhadap pelajaran matematika dan sains. Bukti diawali dengan melakukan validasi isi, memastikan bahwa aitem/indikator mewakili konstrak diungkap. Landasan teori dari sikap menggunakan teori sikap dari Charles Osgood (Azwar, 2014; Divilová, 2016; Gluth dkk, 2010; Periantalo, 2015). Aitem diberikan kepada sekelompok subjek kemudian dianalisis dengan menggunakan analisis faktor konfirmatori guna memberikan dukungan validitas bukti struktur internal (Bolarinwa, 2015; Lewis, 2017; Periantalo, 2018; Sireci \& Padila, 2014; Watson, 2017). Mahasiswa Kedokteran secara berturut diketahui paling menyenangi pelajaran biologi, dilanjutkan dengan pelajaran kimia dan pelajaran matematika serta pelajaran fisika di urutan terakhir (Fitri, Periantalo, Istarini, 2014).

Skala sikap yang dikonstruksikan dapat dimanfaatkan dalam proses pemilihan peminatan SMA ataupun jurusan perkuliahan. Salah satu kriteria alat ukur psikologi yang baik adalah

Jurnal Penelitian dan Pengukuran Psikologi, Vol. 9, No. 2, Oktober 2020 
Jelpa Periantalo

Marlita Andhika Rahman

Hera Wahyuni

Fadzlul

memiliki manfaat praktis bagi kehidupan masyarakat (Azwar, 2013; Kurpius \& Stafford, 2006; Periantalo, 2017; Suryabrata, 2004). Siswa yang memiliki sikap yang positif terhadap pelajaran matematika dan sains direkomdasikan ke peminatan ilmu alam. Mahasiswa yang memiliki sikap yang positif pada biologi, dapat direkomendasikan kuliah di jurusan kedokteran, kehutanan, peternakan, dan lain-lain. Instrumen skala sikap tersebut perlu diuji dengan kriteria eksternal untuk memastikan bahwa alat ukur memiliki validitas yang baik (Azwar, 2014; Bolarinwa, 2015: Suryabrata, 2004; Periantalo, 2016; Zumbi \& Chan, 2014).

Menurut teori tes modern, alat ukur yang baik adalah alat ukur yang valid dan validitasnya harus diestimasikan sebagai suatu kesatuan (AERA, APA, \& NCME, 2014; Azwar, 2016; Goodwin \& Leech, 2003; Lenz, \& Wester, 2017; Sireci \& Padilla, 2014: Sumintoro \& Widhiraso, 2015). Validitas dititikberatkan kepada skor yang dihasilkan oleh alat ukur tersebut, bukan kepada tes itu sendiri, yang mana diartikan sebagai sejauh mana skor dari alat ukur mencerminkan keadaan yang sebenarnya dari subjek yang dituju. Validitas ditunjukan melalui bukti dukungan validitas, yaitu isi, respon, struktur internal, hubungan, atau konsekuensi hasil. Skala sikap terhadap pelajaran matematika dan sains sudah didukung oleh isi dan struktur internal yang baik (Dimitrov, 2010; Lewis, 2017; Schreiber, 2010; Watson, 2017). Alat ukur tersebut perlu dilakukan uji validitas dengan alat ukur atau variabel lain sehingga dapat digunakan untuk keperluan lebih luas (Azwar, 2016; Devellis, 2003; Sumitro \& Widhiarso, 2015).

Penelitian ini bertujuan melihat bukti validitas berkaitan dengan variabel lain sebagai bagian dari konsep validitas menurut teori tes modern (AERA, APA, \& NCME, 2014). Sebuah alat ukur yang baik menunjukkan suatu hubungan dengan variabel lain baik secara positif, negatif atau tidak berhubungan. Informasi tersebut penting untuk dimiliki oleh alat ukur yang memiliki fungsi sebagai tes seleksi atau tes penempatan karena tes tersebut membutuhkan pengukuran yang tepat (Azwar, 2017; Balkin, 2017; Bolarinwa Goodwin
Validasi Skala Sikap Terhadap Pelajaran Matematika Dan Sains

\& Leech, 2003; Sireci \& Padilla, 2014). Adapun alat ukur yang menjadi kriteria hubungan adalah Tes Potensi Akademik, Tes Minat Indonesia spesifikasi minat ilmu kesehatan, serta Ujian Nasional dari setiap pelajaran. Peneliti mengajukan hipotesis bahwa terdapat hubungan positif antar variabel yang diuji.

\section{Metode Penelitian}

Variabel utama dalam penelitian ini adalah skala sikap terhadap pelajaran matematika, fisika, kimia, dan biologi. Penelitian ini menggunakan dasar teori sikap Charles Osgood dan mengartikan sikap sebagai pandangan positif terhadap suatu objek (Azwar, 2014; Chráskaa, \& Chráskováa, 2016; Divilová, 2016; Periantalo, 2017; Periantalo, Fadzlul \& Islamiah, 2018). Dalam sikap tersebut, terdapat tiga komponen, yaitu; potensi, evaluasi dan aktivitas. Variabel yang menjadi kriteria pertama adalah Tes Potensi Akademik, yang terinspirasi dari PAPS UGM (Azwar, 2014; Periantalo, 2015; Widhiarso, 2019; Periantalo, 2018; Raudhod \& Periantalo, 2017). Variabel kriteria kedua adalah Tes Minat Indonesia spesifikasi minat ilmu kesehatan yang mana alat ukur digunakan untuk mengidentifikasi kesukaan terhadap suatu objek yang mendatangkan kesenangan berkelanjutan (Periantalo, 2017; Kyriazos, \& Stalikas, 2018; Nwafor \& Oka, 2018). Minat ilmu kesehatan dispesifikkan ke beberapa subminat, yaitu medis, keperawatan, kesehatan masyarakat, gizi, kedokteran gigi, farmasi, dan anatomi manusia. Variabel kriteria ketiga adalah nilai Ujian Nasional siswa, yang merupakan indikator pencapaian akademik siswa atas hasil pembelajaran dari materi di sekolah.

Subjek penelitian ini adalah mahasiswa baru Fakultas Kedokteran dan Ilmu Kesehatan Universitas Jambi tahun akademik 2014/2015 dan 2015/2016. Setiap mahasiswa baru program studi kedokteran, keperawatan, kesehatan masyarakat dan psikologi Fakultas Kedokteran dan Ilmu Kesehatan Universitas Jambi mendapatkan asesmen psikologis di awal masa registrasi. 
Jelpa Periantalo

Marlita Andhika Rahman

Hera Wahyuni

Fadzlul

Skala sikap terhadap pelajaran dilakukan validitas stuktur internal faktor dengan analisis faktor konfirmatori (Dimitrov, 2010; Lewis, 2017; Schreiber, 2010; Watson, 2017). Reliabilitas tes paralel menunjukkan koefisien ekivalensi sebesar 0,92 (Periantalo, Fadzlul, Saputra, 2014). Tes Potensi Akademik memiliki validitas kriteria dengan SPM sebesar 0,67; Siswa sekolah unggul memiliki skor yang lebih tinggi dengan siswa sekolah biasa dengan $\mathrm{t}=11,705(\mathrm{p}=0,00 ; \mathrm{p}<0,01)$; reliabilitas konsistensi internal sebesar $\alpha=0,87$ (Periantalo, 2018), memiliki norma terstandardisasi TPA maupun IQ Wechsler (Periantalo dan Raudah, 2017). Minat ilmu Kesehatan menggunakan instrumen Tes Minat Indonesia yang terdiri dari minat di perguruan tinggi (Periantalo, 2014, 2017, 2018). Secara konsep Tes Minat Indonesia mengambarkan minat terhadap jurusan kuliah di Indonesia. Aitem dibuat berdasarkan karakteristik dari masing-masing program studi. Hal merupakan metode dalam mencapai validitas isi yang baik sesuai tujuan akhir (Murray, Daoust \& Chen, 2017; Azwar, 2017; Lambie, Blount \& Mullen, 2017; Lenz, \& Wester, 2017, Pepper dkk, 2018). Instrumen tersebut sudah dilakukan validitas kelompok, terdapat perbedaan antara minat ilmu kesehatan antara mahasiswa Ilmu Kesehatan dengan Ilmu Psikis $\mathrm{t}=11.824 ;(\mathrm{p}=.000 ; \mathrm{p}<0.001)$, yang mana mahasiswa ilmu kesehatan memiliki skor yang jauh lebih tinggi dari mahasiswa ilmu psikis pada minat ilmu kesehatan (Periantalo, Iranda, Fadzlul, 2020; Periantalo, Saputra, Sarman, 2019). Instrumen keempat adalah Ujian Nasional mahasiswa pada pelajaran matematika, fisika, kimia dan biologi.

Pada penelitian ini, subjek mendapatkan beberapa pengukuran yang menggunakan tiga alat ukur berbeda. Pada bagian pertama, peserta mendapatkan Tes Minat Indonesia sub minat ilmu kesehatan. Pada tes tersebut, subjek diminta untuk memilih 7 dari 99 alternatif pilihan jawaban, yang kemudian dilanjutkan dengan perangkingan dari satu sampai tujuh sesuai dengan urutan minat yang paling disukainya. Data ini dimaksudkan untuk
Validasi Skala Sikap Terhadap Pelajaran Matematika Dan Sains menjadi bukti validitas berdasarkan respon (Peterson, Peterson, \& Powell, 2017). Pada bagian kedua tes, subjek mendapatkan soal dari Tes Potensi Akademik sub bagian kuantitatif, dalam hal ini adalah pertanyaan mengenai deret angka. Subjek diminta untuk memilih salah satu jawaban yang benar dari lima pilihan yang disediakan berdasarkan nalar logikanya. Di bagian terakhir pengukuran, subjek mendapatkan alat ukur skala sikap untuk setiap pelajaran. Subjek diminta untuk memberikan pandangannya terhadap setiap pelajaran yang diberikan melalui kontinum dua kata sifat yang dikenal dengan semantif differential (Azwar, 2015; Chráskaa, \& Chráskováa, 2016; Divilová, 2016).

Konstruksi alat ukur merupakan bagian dari penelitian kuantitatif psikologi yang membutuhkan analisis Statistika (Azwar, 2017; Hadi, 2015; Periantalo, 2016). Penelitian ini melihat hubungan alat ukur satu dengan alat ukur yang lain dengan menggunakan teknik korelasi (r). Apabila terdapat hubungan antara variabel yang dibandingkan, analisis dilanjutkan dengan regresi $\left(\mathrm{R}^{2}\right)$, untuk melihat kontribusi variabel $\mathrm{X}$ terhadap Y. Analisis data dilakukan dengan menggunakan software JASP 0.9.20 (Jeffrey's Amazing Statistics Program).

\section{Hasil Penelitian}

Sebelum melakukan uji hipotesis, uji asumsi data dilakukan terlebih dahulu guna melihat apakah data tersebut terdistribusi secara normal atau tidak. Korelasi Pearson Product Moment menjadi pilihan untuk data terdistribusi normal, sedangkan Spearman Rho dipilih jika data tidak terdistribusi normal. Apabila terdapat hubungan diantara variabel tersebut, analisis dilanjutkan dengan regresi $\left(\mathrm{R}^{2}\right)$, untuk melihat sumbangan efektif. Setelah dilakukan analisis uji normalitas data, sebagian besar data tersebut tidak normal sehingga uji analisis korelasi yang dilakukan adalah analisis Spearman Rho. 
Tabel 1. Korelasi Sikap terhadap Pelajaran Matematika dan Sains dengan Tes Potensi Akademik

\begin{tabular}{ll}
\hline \multicolumn{2}{c}{ Tes Potensi Akademik } \\
\hline Sikap Matematika & $0,238^{* *}$ \\
Sikap Fisika & $-0,004$ \\
Sikap Kimia & $0,200^{* *}$ \\
Sikap Biologi & $0,163^{* *}$ \\
\hline
\end{tabular}

$* \mathrm{p}>0.05 ; * * \mathrm{p}>0.01$

Hasil uji korelasi menunjukkan terdapat hubungan positif rendah antara Tes Potensi Akademik dengan sikap terhadap pelajaran matematika, kimia dan biologi. Hal tersebut menunjukkan bahwa siswa yang memiliki skor TPA yang tinggi, ada kemungkinan ia memiliki skor yang tinggi pula pada skor sikap terhadap pelajaran matematika, fisika, dan biologi. Siswa yang cerdas secara kognitif diasumsikan memiliki sikap yang positif pada pelajaran matematika, kimia dan biologi. Hal tersebut menunjukkan kontribusi TPA dalam menjelaskan sikap terhadap pelajaran matematika sebesar 5.6\% $\left(\mathrm{R}^{2}=0.056\right)$, sikap terhadap pelajaran kimia sebesar $4 \%$ $\left(\mathrm{R}^{2}=0.0400\right)$, dan sikap terhadap biologi sebesar $2,6 \% \quad\left(\mathrm{R}^{2}=0.026\right)$, dan sisanya dijelaskan oleh faktor lain yang tidak diteliti pada penelitian ini. Tidak ada hubungan yang signifikan antara TPA dengan sikap terhadap pelajaran fisika.

Tabel 2 Korelasi Sikap terhadap Pelajaran Matematika dan Sains dengan Tes Minat

\begin{tabular}{cc}
\hline Tes Minat Indonesia (Minat ilmu kesehatan) \\
\cline { 2 - 2 } Sikap Matematika & 0.085 \\
Sikap Fisika & 0.056 \\
Sikap Kimia & $0.148^{* *}$ \\
Sikap Biologi & $0.173^{* *}$ \\
\hline
\end{tabular}

$$
* \mathrm{p}>0.05 ; * * \mathrm{p}>0.01
$$

Hasil uji korelasi menunjukkan terdapat hubungan positif yang signifikan antara sikap terhadap pelajaran biologi dan kimia terhadap nilai Tes Minat Indonesia spesifikasi minat ilmu kesehatan. Hal ini menunjukkan bahwa siswa yang memiliki minat tinggi pada ilmu kesehatan juga memiliki sikap positif terhadap pelajaran biologi dan kimia. Hasil analisis regresi menunjukkan bahwa Tes Minat Indonesia spesifikasi minat ilmu kesehatan mampu menjelaskan sikap terhadap pelajaran Biologi sebesar $2.9 \%\left(\mathrm{R}^{2}=0,029\right)$ dan menjelaskan sikap terhadap pelajaran kimia sebesar $2.1 \% \quad\left(\mathrm{R}^{2}=0,021\right)$. Menariknya, tidak terdapat hubungan yang signifikan antara Tes Minat Indonesia spesifikasi minat ilmu kesehatan dengan sikap terhadap pelajaran matematika dan fisika. 
Tabel 3 Korelasi Sikap terhadap Pelajaran Matematika dan Sains dengan Nilai Ujian Nasional

\begin{tabular}{llcc}
\hline & Ujian Sekolah & Ujian Nasional & Nilai Akhir \\
\hline Sikap Matematika & $0.373^{* *}$ & 0.040 & 0.148 \\
Sikap Fisika & 0.111 & 0.136 & 0.141 \\
Sikap Kimia & $0.235^{*}$ & 0.007 & 0.136 \\
Sikap Biologi & 0.026 & $-0,086$ & 0.026 \\
\hline
\end{tabular}

$* p>0.05 ; * * p>0.01$

Hasil uji korelasi menunjukkan terdapat hubungan positif antara sikap terhadap pelajaran matematika dengan nilai Ujian Nasional pelajaran matematika. Hal tersebut menunjukkan bahwa siswa yang memiliki skor yang tinggi pada pada sikap terhadap pelajaran matematika cenderung memiliki nilai Ujian Nasional yang tinggi. Uji tersebut menunjukan bahwa sebanyak $13 \%\left(\mathrm{R}^{2}=0,13\right)$ sikap terhadap pelajaran matematika mampu menjelaskan nilai Ujian Nasional pelajaran matematika. Selain itu, sikap siswa terhadap pelajaran kimia juga mampu menjelaskan nilai Ujian Nasional pada pelajaran kimia sebesar 5.52\% $\left(\mathrm{R}^{2}=0,0552\right)$.

\section{Pembahasan dan Diskusi}

Dalam ilmu kesehatan, materi pembelajaran berhubungan erat dengan pelajaran biologi dan kimia. Pelajaran biologi berkaitan dengan cara kerja tubuh manusia sehingga besar kemungkinkan memiliki hubungan positif paling tinggi di bandingkan tiga pelajaran lainnya. Selain itu, pelajaran kimia juga besar kemungkinan berkaitan erat di ilmu kesehatan karena mahasiswa ilmu kesehatan mempelajari obat-obatan yang berhubungan dengan konsep pembelajaran kimia. Dugaan tersebut didukung oleh temuan Fitri, Periantalo \& Attarini (2014). Menurut teori tes klasik, konsep tersebut disebut juga validitas konvergen dan diskriminan (Azwar, 2013; Balkin, 2017; DeVellis, 2003; Goodwin \& Leech, 2003; Supratiknya, 2014; Periantalo, 2017), yang mana validitas konvergen berkaitan dengan hal yang setara sehingga hasil uji korelasinya menghasilkan korelasi positif. Sebaliknya, hasil uji validitas diskriminan yang menggunakan kriteria variabel yang tidak setara tidak akan menghasilkan hubungan yang signifikan.

Nilai prestasi akademik adalah kriteria yang penting bagi skala sikap terhadap pelajaran terutama untuk pelajaran yang digunakan dalam tes seleksi (Azwar, 2013; AERA, APA, \& NCME, 2014; Bolarinwa, 2015; Chen, 2018; DeVellis, 2003; Urbina, 2004; Periantalo, 2015; ). Temuan pada penelitian ini menunjukkan adanya dua mata kuliah yang mendapatkan penilaian sikap positf serta memiliki hubungan positif dengan prestasi akademik. Penelitian ini adalah penelitian awal yang hanya melibatkan subjek penelitian dari mahasiswa kedokteran. Variasi nilai yang didapatkan masih terbatas dan cenderung setara. Dikarenakan keberagaman antar subjek yang cukup setara, fluktuasi skor yang didapatkan tidak bergitu mencerminkan hubungan antar variabel (Azwar, 2013; Dimitrov, 2017; Hadi, 2015; Periantalo, 2016; Sanchal \& Sharma, 2017: Schoot, Lugtig, \& Hox, 2012). Namun, hasil yang didapatkan dari penelitian ini cukup memuaskan. Sebagi tes yang ditujukan sebagai tes seleksi penempatan, skala sikap terhadpa pelajaran matematika dan sains yang diuji pada penelitian ini diketahui cocok untuk digunakan sesuai tujuannya. Instrumen dapat digunakan sebagai instrumen evaluasi pembelajaran serta menjadi bahan pembelajaran di kelas maupun digunakan untuk proses penjurusan siswa SMA di kelas $X$ ataupun penjurusan kuliah.

\section{Kesimpulan}

Hasil penelitian menunjukkan bahwa terdapat hubungan positif yang signifikan antara Tes Potensi Akademik dengan sikap tehadap 
Jelpa Periantalo

Marlita Andhika Rahman

Hera Wahyuni

Fadzlul

pelajaran Matematika, Kimia dan Biologi. Sementara, tidak ada hubungan dengan sikap terhadap Fisika. Terdapat hubungan positif Minat Ilmu Kesehatan Tes Minat Indonesia dengan sikap terhadap pelajaran biologi dan kimia. Hasil penelitian ini menunjukkan adanya hubungan positif skala sikap terhadap pelajaran matematika dan kimia dengan nilai ujian sekolah. Hasil penelitian ini memperkokoh bukti validitas Skala sikap terhadap pelajaran matematika dan sains sehingga sangat kuat dalam mendiagnosis sikap terhadap pelajaran. Penelitian berikutnya melakukan uji validitas dengan kriteria prestasi akademik dengan subjek yang lebih luas, baik itu nilai siswa SMA maupun IPK mahasiswa di suatu program studi.

\section{Rekognisi}

Penelitian ini didanai oleh DIPA PNBP Fakultas Kedokteran dan Ilmu Kesehatan Universitas Jambi Tahun 2019 Skema Penelitian C.

\section{Daftar Pustaka}

AERA, APA, \& NCME. (2014). Standards for Educational and Psychological Testing. Washington, DC: American Educational Research Association.

Azwar, S. (2013). Reliabilitas dan validitas. Pustaka Pelajar: Yogyakarta.

Azwar, S. (2014). Sikap manusia: Teori dan pengukurannya. Pustaka Pelajar: Yogyakarta.

Azwar, S. (2014). Penyusunan skala psikologi. Ed. Ke-2. Pustaka Pelajar: Yogyakarta.

Azwar, S. (2014). Konstruksi tes kognitif. Pustaka Pelajar: Yogyakarta.

Azwar, S. (2016). Dasar-dasar psikometri. Ed. Ke2. Pustaka Pelajar: Yogyakarta.

Azwar, S. (2017). Metode penelitian psikologi. Ed. Ke-2. Pustaka Pelajar: Yogyakarta.
Validasi Skala Sikap Terhadap Pelajaran Matematika Dan Sains

Balkin, R. S. (2017). Evaluating evidence regarding relationships with criteria. Measurement and Evaluation in Counseling and Development, 50 (4), 264269. doi:10.1080/07481756.2017.1336928

Bolarinwa, O. A. (2015) Principles and methods of validity and reliability testing of questionnaires used in social and health science researches. Nigerian Postrgraduate Medical Journal, 22, 195201.

Chráskaa, C. \& Chráskováa, M. (2016). Semantic differential and its risks in the measurement of students' attitudes. Procedia - Social and Behavioral Sciences, 217, $820-829$.

DeVellis, R. F. (2003). Scale development: Theory and application. Thousand Oaks: New York.

Dimitrov, D. M. (2010). Testing for factorial invariance in the context of construct validation. Measurement and Evaluation in Counseling and Development, 43 (2), 121149. doi:10.1177/0748175610373459

Divilová, S. (2016). Semantic differential as one of the research tools suitable for establishing the attitudes of pupils to old age and seniors. Universal Journal of Educational Research 4 (8): 1858-1862.

Fitri, A. D., Periantalo, J., \& Istarini A. (2014). Sikap mahasiswa program studi pendidikan dokter 2013 Fakultas Kedokteran dan Ilmu Kesehatan Universitas Jambi terhadap pelajaran matematika dan sains. Jambi Medical Journal 'Jurnal Kedokteran dan Kesehatan', 1 (2), 56-76.

Goodwin, L.D. \& Leech, N.L. (October, 2003). The meaning of validity in the new 
Jelpa Periantalo

Marlita Andhika Rahman

Hera Wahyuni

Fadzlul

standard for educational and psychological testing: implication for measurement course. Journal of Measurement and Evaluation in Counseling and Development, 36, 181-191.

Gluth, S., Ebner, N. E., \& Schmiedek, F. (2010). Attitudes toward younger and older adults: The German aging semantic differential. International Journal of Behavioral Development, 34 (2), 147-158.

Hadi, S. (2015). Metodologi riset. Yogyakarta: PustakaPelajar.

Hadi, S. (2015). Statistika. Yogyakarta: PustakaPelajar.

Kurpius, S. E. R., Stafford, M.E. (2006). Testing and measurement: A user-friendly guide. California: Thousand Oaks.

Kyriazos, T. A., Stalikas, A. (2018). Applied Psychometrics: The steps of scale development and standardization Process. Psychology, 9, 2531-2560

Lang, C. L. et. al. (2018). Positive attitude toward math supports early academic success: Behavioral evidence and neurocognitive mechanisms. Psychological Science, 29 (3), 390-402. doi: 10.1177/0956797617735528.

Lambie, G. W., Blount, A. J., \& Mullen, P. R. (2017). Establishing content-oriented evidence for psychological assessments. Measurement and Evaluation in Counseling and Development, 50 (4), 210-216. doi:10.1080/07481756.2017.1336930

Lenz, A. S., \& Wester, K. L. (2017). Development and evaluation of assessments for counseling professionals. Measurement and Evaluation
Validasi Skala Sikap Terhadap Pelajaran Matematika Dan Sains

in Counseling and Development, 50, 201209.

Lewis, T. F. (2017). Evidence regarding the internal structure: Confirmatory factor analysis. Measurement and Evaluation in Counseling and Development, 50 (4), 239247. doi:10.1080/07481756.2017.1336929.

Murray, A. K., Daoust, C.D., Chen, J. (2019). Developing instruments to measure Montessori Instructional Practices. Journal of Montessori Research 5 (1), 1-25.

Nwafor C. E. \& Oka, O. O. (2018). Secondary school students' interest inventory in Biology. International Journal of Humanities Social Sciences and Education, 44-59.

Periantalo, J., Fadzlul, F., \& Saputra, N. E. (2014). Konstruksi skala sikap terhadap pelajaran Matematika dan Sains. Edu-Sains: Jurnal Pendidikan Matematika dan Ilmu Pengetahuan Alam, 3 (2), 36-45.

Periantalo, J. (2015). Penyusunan skala psikologi: asyik, mudah dan bermanfaat. Pustaka Pelajar: Yogyakarta.

Periantalo, J. (2015). Validitas alat ukur psikologi: Applikasi praktis. Yogykarta: Pustaka Pelajar.

Periantalo, J. (2016). Penelitian kuantitatif untuk psikologi. Yogyakarta: Pustaka Pelajar.

Periantalo, J. (2016). Penyusunan skala sikap terhadap pelajaran dasar sebagai upaya optimalisasi pembelajaran. Jurnal Penelitian Universitas Jambi: Seri Humaniora 18 (2).

Periantalo, J. (2017). Statistika dasar untuk psikologi. Yogykarta: Pustaka Pelajar. 
Jelpa Periantalo

Marlita Andhika Rahman

Hera Wahyuni

Fadzlul

Periantalo, J. (2017). Uji validitas konstrak Tes Minat Indonesia melalui aspek minat psikis. Psycho Idea, 15 (1), 9-17.

Periantalo, J. \& Azwar, S. (2017). Pengembangan skala kepribadian siswa SMA dari tipologi kepribadian Jung dan Myers-Briggs. Jurnal Sains Sosio Humaniora, 1 (2), 191-207.

Periantalo, J. (2018). Propertis psikometris skala sikap terhadap pelajaran sosial humaniora. Jurnal Ilmu Perilaku, 1 (2), 98-109.

Periantalo, J. (2018). Uji validitas konstrak Tes Minat Indonesia melalui komponen kesehatan. Psycho Idea, 16 (1), 39-50.

Periantalo, J. (2018). Validitas kriteria Tes Potensi Akademik Unja (Criterion related validity of TPA Unja). Intuisi: Jurnal Psikologi Ilmiah, 10 (1), 1-9.

Periantalo, J., Fadzlul, F., \& Islamiah, R. (2019). Penyusunan skala sikap terhadap pelajaran praktis. Jurnal Psikohumanika, 11 (1), 119.

Periantalo, J., Saputra, E., \& Sarman, F. (2019). Validitas kelompok minat ilmu psikis Tes Minat Indonesia dengan TPA dan skala sikap terhadap pelajaran. Jurnal Pengukuran Psikologi dan Pendidikan Indonesia, 8 (1), 7-12.

Periantalo, J. J., Iranda, A., \& Fadzlul, F. (2020). Uji validitas Tes Minat Indonesia komponen ilmu kesehatan dengan skala sikap terhadap pelajaran. Psikoislamedia: Jurnal Psikologi, 4 (1), 114-123.

Pepper, D., Hodgen, J., Lamesoo, K., Kõiv, P., \&T olboom, J. (2018). Think aloud: using cognitive interviewing to validate the PISA assessment of student self-efficacy in mathematics. International Journal of
Validasi Skala Sikap Terhadap Pelajaran Matematika Dan Sains

Research \& Method in Education, 41 (1), 3-16. doi:10.1080/1743727X.2016.1238891

Peterson, C. H., Peterson, N. A., \& Powell, K. G. (2017). Cognitive interviewing for item development: validity evidence based on content and response processes. Measurement and Evaluation in Counseling and Development, 50 (4), 217223. doi:10.1080/07481756.2017.1339564

Raudhoh, S. \& Periantalo, J. (2017). Norma empirik Tes Potensi Akademik (TPA) Universitas Jambi untuk kelompok mahasiswa. Jurnal Psikologi Jambi, 2 (2), 10-16.

Sanchal, A., \& Sharma, S. (2017). Students' attitude toward learning Mathematics: Impact of teaching in a sporting context. Teachers and Curriculum, 17 (1), 89-99.

Schreiber, J. B., Nora, A., Stage, F. K., Barlow, E. A., \& King, J. (2006). Reporting structural equation modeling and confirmatory factor analysis results: a review. The Journal of Educational Research, 99 (6), 323-338. doi:10.3200/JOER.99.6.323-338

Sireci, S. \& Padilla, J. L. (2014). Validating assessments: Introduction to the special section. Psicothema, 26 (1), 97-99. doi: 10.7334/psicothema2013.255.

Sumintoro, B., \&Widhiarso, W. (2015). Applikasi Rasch model untuk penelitian ilmu-ilmu sosial. Bandung: Trim Komunikata.

Sumintoro, B., \&Widhiarso, W. (2015). Aplikasi pemodelan Rasch pada asesmen pendidikan. Bandung: Trim Komunikata.

Suryabrata, S. (2004). Penyusunan alat ukur Psikologi. Penerbit Andi: Yogyakarta. 
Supratiknya, A. (2014). Pengukuran psikologis. Yogyakarta: Penerbit Universitas Sanata Darma.

Urbina, S. (2004). Essential of psychological testing. Hoboken: John Wiley \& Sons.

Watson, J. C. (2017). Establishing evidence for internal structure using exploratory factor analysis. Measurement and Evaluation in Counseling and Development, 50 (4), 232238. doi:10.1080/07481756.2017.1336931

Widhiarso, W. (2019). Pembuktian validitas terkait struktur Tes Potensi Akademik Pascasarjana (PAPS) Universitas Gadjah Mada. Jurnal Psikologi, 46 (2), 145-162.

Wood, T. T., \& Knezek, G., Christensen, R. (2010). Instruments for assessing interest in STEM content and careers. Journal of Technology and Teacher Education, 18 (2), 341-363.

Van de Schoot, R., Lugtig, P., \& Hox, J. (2012). A checklist for testing measurement invariance. European Journal of Developmental Psychology, 9 (4), 486-492. doi:10.1080/17405629.2012.686740

Zumbo, B.D. \& Chan E.K.H. (2014). Validity and validation in social, behavioral and health sciences. Springer. 